\title{
Randomised controlled trial of a 12 week yoga intervention on negative affective states, cardiovascular and cognitive function in post-cardiac rehabilitation patients
}

Alan Yeung ${ }^{1}$, Hosen Kiat ${ }^{2}$, A Robert Denniss ${ }^{3}$, Birinder S Cheema ${ }^{1}$, Alan Bensoussan ${ }^{1}$, Bianca Machliss ${ }^{4}$, Ben Colagiuri ${ }^{5}$ and Dennis Chang ${ }^{\text {* }^{*}}$

\begin{abstract}
Background: Negative affective states such as anxiety, depression and stress are significant risk factors for cardiovascular disease, particularly in cardiac and post-cardiac rehabilitation populations.

Yoga is a balanced practice of physical exercise, breathing control and meditation that can reduce psychosocial symptoms as well as improve cardiovascular and cognitive function. It has the potential to positively affect multiple disease pathways and may prove to be a practical adjunct to cardiac rehabilitation in further reducing cardiac risk factors as well as improving self-efficacy and post-cardiac rehabilitation adherence to healthy lifestyle behaviours.

Method and design: This is a parallel arm, multi-centre, randomised controlled trial that will assess the outcomes of post- phase 2 cardiac rehabilitation patients assigned to a yoga intervention in comparison to a no-treatment wait-list control group. Participants randomised to the yoga group will engage in a 12 week yoga program comprising of two group based sessions and one self-administered home session each week. Group based sessions will be led by an experienced yoga instructor. This will involve teaching beginner students a hatha yoga sequence that incorporates asana (poses and postures), pranayama (breathing control) and meditation. The primary outcomes of this study are negative affective states of anxiety, depression and stress assessed using the Depression Anxiety Stress Scale. Secondary outcomes include measures of quality of life, and cardiovascular and cognitive function. The cardiovascular outcomes will include blood pressure, heart rate, heart rate variability, pulse wave velocity, carotid intima media thickness measurements, lipid/glucose profiles and C-reactive protein assays. Assessments will be conducted prior to (week 0), mid-way through (week 6) and following the intervention period (week 12) as well as at a four week follow-up (week 16).

Discussion: This study will determine the effect of yoga practice on negative affective states, cardiovascular and cognitive function in post-phase 2 cardiac rehabilitation patients. The findings may provide evidence to incorporate yoga into standardised cardiac rehabilitation programs as a practical adjunct to improve the management of psychosocial symptoms associated with cardiovascular events in addition to improving patients' cognitive and cardiovascular functions.
\end{abstract}

Trial Registration: ACTRN12612000358842

Keywords: Yoga, Anxiety, Stress, Depression, Cardiac rehabilitation

\footnotetext{
* Correspondence: d.chang@uws.edu.au

${ }^{1}$ National Institute of Complementary Medicine, School of Science and Health, University of Western Sydney, Locked Bag 1797, Penrith, NSW 2751,

Australia

Full list of author information is available at the end of the article
}

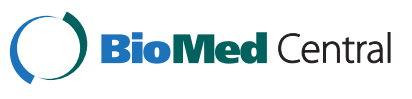

(c) 2014 Yeung et al.; licensee BioMed Central Ltd. This is an Open Access article distributed under the terms of the Creative Commons Attribution License (http://creativecommons.org/licenses/by/4.0), which permits unrestricted use, distribution, and reproduction in any medium, provided the original work is properly credited. The Creative Commons Public Domain Dedication waiver (http://creativecommons.org/publicdomain/zero/1.0/) applies to the data made available in this article, unless otherwise stated. 


\section{Background}

Cardiovascular disease (CVD) is a leading cause of morbidity and mortality worldwide. In 2004, CVD caused 17.1 million deaths and this is estimated to increase to 23.6 million by 2030 [1]. This increase is paralleled by an increase in the prevalence of psychological risk factors such as anxiety, depression, and stress that have been shown to be associated with CVD morbidity and mortality [2,3]. Anxiety and depression are common after CVD events with prevalence rates up to $31 \%$. Interestingly, anxiety and depression in CVD patients appear to be independent of functional health, time between cardiac incidents, and enrolment in cardiac rehabilitation (CR) programs [4-6]. Furthermore, these psychosocial factors often cluster within an individual with a significant number of patients presenting with multiple psychological symptoms upon CR entry [5]. This evidence is particularly concerning as these affective symptoms have been shown to increase the risk of primary and subsequent cardiovascular events, and contribute to poor behavioural aspects that affect general cardiovascular health [7-9]. While anxiety and depression are distinctly separate at a conceptual level, past attempts to quantify these constructs yielded high degrees of intercorrelation [10]. This has resulted in the development of a tripartite continuum with anxiety and depression at opposite extremes and a centralised nonspecific component, which encompasses key aspects of stress [11].

Numerous studies have demonstrated that psychosocial stress is a significant risk factor for CVD in both patients with established disease and healthy individuals $[7,12]$ and large scale community-based studies as well as prospective studies have found significant relationships and prevalence rates between anxiety, depression and CVD risk [13-15]. Whilst the precise physiological and biochemical mechanisms that underlie the bidirectional associations between these negative affective states and CVD are not well understood, a number of studies have implicated hypothalamic-pituitary-adrenal axis dysfunction, activation of pro-inflammatory cytokines, autonomic dysregulation and increased markers of inflammation as possible key neurobiological mechanisms [16-18]. In addition to this, previous evidence indicates negative behavioural patterns in patients with high anxiety or depression such as less contact with their cardiologists, being less likely to seek preventative medical care, poorer medication compliance as well as reduced self-motivational, and physical inactivity that further worsens cardiac outcomes $[5,19]$. Furthermore, patients with anxiety or depression, even at subclinical levels exhibit significantly lower quality of life (QoL) scores [5,20].

In an attempt to reduce the prevalence and progression of CVD, cardiac rehabilitation and prevention programs which incorporate exercise regimens, stress management techniques and patient education, have gained widespread acceptance and have been shown to improve risk factor management and functional capacity thereby reducing the chance of secondary cardiovascular incidences [21]. CR programs have also been shown to improve cognitive function, QoL, and psychosocial outcomes and programs with an exercise component also have benefits on mortality. However in spite of these benefits, CR programs remain underutilised with only an estimated $30 \%$ of eligible patients in Australia participating [22,23]. Whilst it is widely believed that continued exercise and physical activity is required to sustain most of the benefits gained through the participation of CR, studies have reported an adherence rate to physical activity of $30 \%$ to $60 \%$ in those who complete phase 2 rehabilitation programs [24,25]. This has been highlighted in a study of myocardial infarction (MI) patients where CR benefits diminished to a level in which no significant differences between CR and nonCR participants could be seen 6 months post-MI [26]. Therefore, a practical adjunct which can improve physiological and psychosocial risk factors may further reduce cardiac risk factors and improve self-efficacy and longterm adherence to healthy behaviours.

Yoga may be one such treatment [27]. It is described as a path, which integrates the body, senses, mind, and intelligence with the self and numerous studies have reported the benefits of yoga in reducing stress, anxiety, and depressive symptoms in healthy and psychologically affected volunteers [28-30]. This is consistent with numerous reviews that highlight the positive potential of yoga for the treatment of depressive and anxiety disorders [31-34]. Whilst the methodological quality of prior yoga studies are generally weak, there are multiple reviews that highlight the favourable effects of yoga in improving the cardiovascular profile across a range of clinical and healthy populations [35-37]. Significant improvements in a wide range of cardiovascular parameters such as the high frequency component of heart rate variability (HRV), pulse wave velocity (PWV), blood lipid profiles (low density / high density lipoproteins and triglycerides), and C-reactive proteins (CRP) highlights the broad range of effect yoga has on the cardiovascular system [37-45]. Hatha yoga is consider to achieve benefits in blood circulation by enhance the effect of circulatory pumps in the body. Dynamic exercises such as vinyasas focus on activating and relaxing muscles during movement to enhance the effects of the musculoskeletal pump. Furthermore co-activation of antagonistic muscles during vinayasas and static postures (asanas) can create regions of relatively low and high pressures to augment muscle co-activation and postural circulation pumps to improve blood circulation [46].

To complement the array of psychosocial and cardiovascular impact of yoga, recent studies linking the 
detrimental effects of CVD and arterial stiffness with the decline of cognitive performance provides a framework for the investigation into the effects of yoga and its influence on cognitive function [47-49]. Whilst there are few studies which assess the effect of yoga on neuro-cognition, considering its capacity to improve a wide range of cardiovascular parameters, there may be corresponding improvements in the cognitive profile. Preliminary evidence in a study by Cohen et al. [50] demonstrates a strong association between the executive abilities of focused attention, processing speed, maintenance of effort, and QoL improvements after a yoga intervention in CR patients [50]. Whilst there is a significant body of evidence to support its use in healthy, psychosocially affected and various pathological populations, there are relatively few studies that examine a combination of psychosocial, cardiovascular, and cognitive effects in cardiac or CR populations. Given the impact of yoga across a broad range of health adaptations in various populations, we hypothesise that yoga will improve anxiety, depression and stress accompanied by improvements in cardiovascular parameters of HRV, PWV, CIMT, biomarkers and cognitive function in post-CR patients.

\section{Method and design}

\section{Study design}

This is a two arm, multi-centre, parallel-arm randomised controlled trial that will compare the outcomes of patients with cardiovascular disease assigned to a 12 week yoga intervention or to a no-treatment control group. The study will be conducted in approximately 134 postCR participants over a period of 16 weeks comprising of a 12 week intervention period and 4 week follow up assessment. The primary outcome of this study is the component and overall scores obtained through the Depression Anxiety Stress Subscale (DASS) [51]. Secondary outcomes include QoL and cardiovascular and cognitive function. Timepoints for assessments will take place at baseline (week 0), mid-intervention (week 6), postintervention (week 12), and at follow up (week 16). Ethics approval has been sought from the University of Western Sydney (H9402), Sydney Adventist Hospital Group (2011.40) and Western Sydney Local Health District Human Research Ethics Committees (2013/6/4.5(3747)).

\section{Sample size and power calculation}

To our knowledge, there is at present only one study which examines the effect of yoga training in post-CR patients [52]. This study assessed the effects of a 6 week yoga program on lipid profiles and brachial artery vasodilation in 10 post-CR patients and 23 healthy individuals however published data was insufficient to conduct a preliminary power analysis [52]. Given the DASS is a primary outcome measure in this study, a power analysis was conducted upon the results published in a metaanalysis on yogic effects in depression [34]. Results published by Cramer et al. [34] noted a standardised mean difference of 0.69 compared to usual care across five studies. Application of these findings as a basis for an approximated power calculation resulted in an estimated required sample size of 112 participants. Allowing a 20\% drop-out rate, a total of 134 patients will be recruited in the current study. This power calculation has been conducted based on a population other than post-cardiac rehabilitation due to a lack of available data in this patient cohort to permit a more robust calculation. As such, an interim sample size analysis will also be conducted at $\mathrm{n}=50$ allowing for an acceptable estimate of the population standard deviation and hence considerably more robust sample size calculation to ensure adequate power.

\section{Participants}

Eligibility criteria includes: Adult ( $>18$ years) having proven coronary artery disease and completion of a Phase 2 cardiac rehabilitation program within the past 9 months; available to attend two yoga sessions per week and complete a simplified self-administered yoga program once a week for the duration of the study; not currently or previous engaged in a yoga program ( $>3$ yoga session); no acute or chronic medical conditions which would make yoga potentially hazardous; ability to communicate in English; willingness and cognitive ability to provide written informed consent. Should the participant have any of the following conditions they will be excluded from the trial: pacemakers or implanted defibrillators, pregnancy; end stage congestive heart failure; permanent bed-bound status; unstable abdominal, thoracic or cerebral aneurysm; acute myocarditis, pericarditis, pulmonary embolus or pulmonary infarction; severe cognitive deficits (MMSE $<21$ ); previous or current psychological disorders that are not associated with depression or anxiety.

\section{Randomization}

Participants will be randomized via computer-generated randomly permuted blocks into interventional group or control group. The randomization assignments will be prepared by a National Institute of Complementary Medicine (NICM) Research Program Coordinator who is external to the research team. Group assignment will be delivered to participants in sealed envelopes once the participant is screened and fully enrolled.

\section{Intervention}

\section{Experimental group}

Participants randomised to the yoga therapy group will receive two supervised yoga sessions per week for a period of 12 weeks. They will also be provided with a 
simplified take-home yoga program, which they will be instructed to practice once per week. The yoga sessions will be group-based and led by an experienced yoga instructor from Yoga Synergy Pty Ltd (Sydney, Australia) [46]. These sessions will run twice per week for approximately one hour per session (details of yoga sequence and time requirements outlined in Table 1). The hatha yoga program will be similar to that used by the research team in a previous study [45] and will involve teaching beginner students safely and progressively over 12 weeks incorporating asanas (poses and postures), pranayama

\section{Table 1 Yoga routine}

\begin{tabular}{|c|c|}
\hline \multicolumn{2}{|c|}{ Introductory section } \\
\hline \multirow[t]{4}{*}{5 Minutes } & Utkata Vinyasa \\
\hline & Utkata Danda Nadi Vinyasa \\
\hline & Candra Namaskar \\
\hline & Surya Namaskar \\
\hline \multicolumn{2}{|c|}{ Standing Postures } \\
\hline \multirow[t]{7}{*}{10 Minutes } & Trikonasa Vinyasa \\
\hline & Parsvakona Vinyasa \\
\hline & Gadja Hasta Padottana Vinyasa \\
\hline & Gadja Baddha Padottana Vinyasa \\
\hline & Parsvottonasa Vinyasa \\
\hline & Eka Pada Vinyasa \\
\hline & Virabhadra Vinyasa \\
\hline \multicolumn{2}{|c|}{ Floor Postures } \\
\hline \multirow[t]{5}{*}{10 Minutes } & Pashima Vinyasa \\
\hline & Janu Sirsa Vinyasa \\
\hline & Maricy Vinyasa \\
\hline & Baddha Kona Vinyasa \\
\hline & Pada Sirsa Preparation Vinyasa \\
\hline \multicolumn{2}{|c|}{ Back Bending Sequence } \\
\hline \multirow[t]{3}{*}{5 Minutes } & Adho Viparita Vinyasa \\
\hline & Adho Viparita Vinyasa \\
\hline & Urdhava Dhanura Vinyasa \\
\hline \multicolumn{2}{|c|}{ Back Bend Releasing Sequence } \\
\hline \multirow[t]{2}{*}{5 Minutes } & Urdhva Dhanura Releasing Vinyasa \\
\hline & Hasta Vinyasa \\
\hline \multicolumn{2}{|c|}{$\begin{array}{l}\text { Shoulderstand, Releasing Postures } \\
\text { \& Finishing Postures }\end{array}$} \\
\hline \multirow[t]{3}{*}{10 Minutes } & Sarvangasana Vinyasa \\
\hline & Viparita Mudra Vinyasa \\
\hline & Padma Vinyasa \\
\hline \multicolumn{2}{|c|}{ Pranayam Meditation \& Relaxation } \\
\hline \multirow[t]{3}{*}{15 Minutes } & Nadi Padma Namaskar \\
\hline & Nadi Sodhana Pranayama \\
\hline & Savaasana \\
\hline
\end{tabular}

(breathing control) and savasana (meditation). At the start of each session, a series of introductory movements designed to warm-up the extremities, large joints and spine (itkata vinyasa and utkata danda nadi vinyasa) will be conducted before moving into a salute to the moon (candra namaskar). This will be followed by standing postures which are linked to one another to warm up the body whilst stretching and strengthening the muscles (trikonasa, parsvakona, gadja hasta padottana, gadja baddha padottana, parsvottonasa, eka pada, virabhadra). Following this, a series of floor postures which are also linked together will be conducted and include: forward bends, twists, hip opening, back arches, and back arch releases. As participants become more competent with training, an inversion (shoulderstand) is added to help calm and restore the body and nervous system. This is followed by a series of neck and spine releases to ensure participant safety. Participants then sat on the floor and engaged in breathing exercises (pranayama) and then supine meditation/relaxation (savasana). All postures and exercises are comprised of a simple and more challenging variant to allow difficulty to be scalable within the yoga program in relation to participant ability and capacity.

\section{Control group}

Participants randomised to the wait list control group will receive no instructions about yoga practice for the 16 week trial period (12 week intervention +4 week follow up). Upon their completion of the trial, wait list participants will be given the opportunity to participate within the yoga program.

\section{Outcomes}

Participants will be restricted from consuming caffeine 4 hours prior to and alcohol 24 hours prior to each of the four testing sessions (baseline, mid-intervention, post-intervention, follow-up). This includes caffeinated products such as caffeine tablets (No-Doz, etc.) as well as caffeinated drinks.

\section{Psychological outcomes \\ Depression Anxiety Stress Scales (DASS)}

The DASS is a set of three self-reported scales designed to assess the negative emotional states of depression, anxiety and stress. Each of the three DASS sub-scales contains 14 items, divided into subscales of $2-5$ items with similar content. The DASS has been employed in a number of studies in cardiac populations and has been shown to have good test-retest reliability coefficients for all scales [53]. The DASS scale was found to show better discrimination when assessed in comparison to a wellestablished coronary prone behavioural pattern scale such as the Framingham Scale in a group of Myocardial 
Infarction (MI) and matched control patients [54]. While not as widely used as other questionnaires of anxiety and depression such as the State Trait Anxiety Inventory, Beck Depression Inventory or Beck Anxiety Inventory, the DASS shows greater discriminant validity in regards to these psychosocial factors [11]. Participants will be asked to use 4-point severity/frequency scales to rate the extent to which they have experienced each state over the past week. Overall DASS scores will be calculated and presented for statistical analysis.

\section{Short Form 36 version 2 (SF36v2)}

Short Form 36 is a psychometrically robust and clinically credible 36-item questionnaire that is designed to assess health related quality of life across diverse medical and psychiatric groups $[55,56]$. It has also been shown to be a valid and reliable instrument for assessing physical and mental health status of cardiac patients and that CVD is associated with reductions in health-related QoL [57]. The SF36v2 organises the 36 items into eight components and presented on a percentage scale $(0-100)$ and T-score. These eight components will be combined into two summary measures to provide overall estimates of physical and mental health. SF36v2 will be presented to participant as either a paper based questionnaire or as an electronic survey using Evado clinical trial software (Evado, Melbourne, Australia).

\section{Cardiovascular measurements}

Heart Rate and Blood Pressure: All blood pressure and heart rate measurements will be calculated using an automatic sphygmomanometer, designed for professional use (Omron, Sydney, Australia). Brachial arterial blood pressure will be taken following a 5 minute rest period. This will be done with an automatic sphygmomanometer whilst the participant is sitting comfortably.

Heart Rate Variability (HRV): HRV has been extensively used to assess vagal function and the associations between autonomic imbalance and disease morbidity and mortality [58]. To date, there is a large body of evidence indicating that HRV is an independent predictor of CVD morbidity and mortality in both high and low risk populations [59-62]. Whilst large population studies have highlighted this association as early as the 1980s, recent research has strongly suggests that negative affective states may significantly impacts on HRV, disease and poor health $[63,64]$. Time and frequency domains measurements of HRV have been successfully used to index vagal activity and although there is debate regarding the reflection of Parasympathetic Nervous System (PNS) and/or Sympathetic Nervous System (SNS) influence of low frequency power, high frequency power has been shown to primarily reflect PNS activity with consensus amongst numerous studies is that lower index values of vagal function are associated with disease morbidity and mortality [65]. Three electrocardiogram (ECG) electrode pads will then be placed onto the participant's upper left and upper right chest as well the lower left side of the torso. Participants will be asked to lay supine for 10 minutes during which the SphygmoCor system (AtCor Medical, Sydney, Australia) will capture data for HRV calculation. Data from both time (standard deviation of $\mathrm{R}$ to $\mathrm{R}$ intervals and root mean square successive differences) and frequency (high and low frequency spectral power and ratios) domain variables will be collected and analysed. This will provide indices that reflect the input to the heart from the two major branches of autonomic nervous system, the SNS and PNS.

Pulse Wave Velocity (PWV): Pulse Wave Velocity is generally accepted as the simplest, non-invasive, robust and reproducible method of determining arterial stiffness [66]. Research indicates it has independent predictive value for cardiovascular mortality and morbidity in a wide range of pathological and general populations [67-70]. Non-invasive PWV has been validated against invasive aortic PWV (correlation coefficient $=0.70$ ) with suprasternal notch-femoral minus carotid-suprasternal notch distance showing the best agreement with invasive data [71]. While the participant is still supine, an ECGfemoral and carotid tonometric procedure will also be conducted. PWV procedure will be conducted in accordance to with recommendations outlined in the Expert Consensus Document on Arterial Stiffness [66]. Travel distance will be calculated by subtracting the carotid artery to suprasternal notch distance from the suprasternal notch to femoral artery. A single high fidelity applanation tonometer will then be placed over carotid and femoral arteries and data will be acquired for PWV. Travel time between the two arterial sites will be calculated as the difference between R-waves and the footpoints at their respective sites [71]. Footprint of the pressure wave at both sites will be automatically assessed using the intersecting-tangent method [71]. Calculations will be completed using SphygmoCor Cardiovascular Management Software (AtCor Medical, Sydney, Australia).

Carotid Intima Media Thickness (CIMT): Measurement of CIMT with B-mode ultrasound is a sensitive, non-invasive and reproducible technique for both identification and quantification of subclinical vascular disease and for evaluating CVD risk [72]. Imaging of the carotid artery to identify areas of increased thickness and nonocclusive atherosclerotic plaque which represents early stages of arterial injury and atherosclerosis has increasingly being used as a surrogate cardiovascular endpoint in a number of clinical trials [73]. Whilst there are numerous reviews and studies providing evidence that CIMT is strongly related to CVD incidents and that it is a well validated research tool, variations in methodology 
and sparse clinical data has prevented widespread adoption of this technique for routine assessment in clinical settings [74]. As a result, numerous guideline and consensus statements have been produced in an attempt to standardise CIMT procedures for research and clinical use. CIMT procedures in this study will be conducted in accordance with the Mannheim Carotid Intima-Media Thickness Consensus (2004-2006) [73]. The participant will be asked to lie in a supine position with their head tilted to the side. High resolution B-mode carotid ultrasonography will be performed using a $13 \mathrm{Mhz}$ lineararray transducer on a GE Vivid I ultrasound system (GE Medical, Sydney, Australia). Pre-processing configurations will be held constant during all examinations. The gain is to be adjusted so that the less dense arterial wall interface should be just visible and the image should clear show both near and far vessel walls. The Common Carotid Artery (CCA) will be insonated longitudinally and perpendicular to the vessel wall. Measurements are to be taken from the far wall of the CCA within $10 \mathrm{~cm}$ from the carotid bifurcation and of a minimal measurement length of $10 \mathrm{~mm}$. IMT to be defined as the distance between the luminal-endothelial interface and the junction between the media and adventitia. Mean values of at least 10 measurements at systole are to be used for measurement. Image sets will be assessed for clarity and automatic edge tracking software known as EchoPak (GE Medical, Sydney, Australia) to be used offline to determine averaged mean and maximal IMT values and adventitia to adventitia diameter.

\section{Cognitive function}

Computerised Mental Performance Assessment System (COMPASS): The Computerised Mental Performance Assessment System (COMPASS) features a number of computerised cognitive tasks designed to test various aspects of mental function. The COMPASS test battery has been used in numerous cognitive studies and has been shown to be sensitive to changes in a number of cognitive domains [75-77]. The system employs a range of similarly validated cognitive tasks seen in computerised test suites such as the Cognitive Drug Research computerised assessment system however COMPASS is a purposely designed software application allowing for greater flexibility in choice of tasks and delivery of randomly generated parallel versions of standard cognitive assessment tasks [78]. Data from alternate forms of each task presented during testing sessions will be automatically captured by the COMPASS software.

\section{Biochemistry markers}

Low Density Lipoproteins (LDL), High Density Lipoproteins (HDL) and Triglycerides: Lipid levels, such as low High Density Lipoprotein (HDL) and high Low Density
Lipoprotein (LDL) and triglyceride levels have been shown to be associated with increased risk of CVD [79]. Whilst the initiation of atherosclerosis has been long debated, mounting evidence suggests that LDLs interact with arterial walls allowing for prolonged exposure to local enzymes, both oxidative and non-, leading to modifications of lipoproteins and their constituents [80]. These modified lipoproteins have been suggested to play a role in inflammatory reactions that accelerate lesion development [81]. In contrast, research into HDLs highlight their functionality as being potentially highly vasoprotective in inhibiting endothelial apoptosis, maintain vaso-reactivity, contributing to endothelium repair and reducing adhesion molecule expression [82]. All of these actions may attenuate key processes of atherosclerotic plaque formation. In addition, population studies that provide evidence of associations between low HDLs and CVD risk are strong and consistent $[79,83]$. Lipid profiles will be determined before and after the intervention at weeks 0 and 12. Participants will be sent to have blood samples taken and pathology testing conducted by a reputable pathology collection centre.

Glucose: Similarly to cholesterol, plasma glucose levels have been observed to be a continuous risk factor for CVD with diabetic patients exhibiting at least a 2-fold increase in risk [84]. However as traditional glucose cut off levels were chosen to identify diabetes mellitus and not increased CVD risk, people with elevated but below diabetic glucose concentrations still represent increased risk which has been highlighted in several large population studies [85-87]. Glucose profiles will be determined before and after the intervention at weeks 0 and 12. Participants will be sent to have blood samples taken and pathology testing conducted by a reputable pathology collection centre.

C-reactive protein (CRP): C-Reactive protein (CRP) was initially used as a non-specific biomarker for inflammatory processes however has become a powerful independent modifiable predictor of CVD in various clinical and non-clinical populations [88,89]. The Centre for Disease Control and Prevention and the American Heart Association have issued a Class IIa recommendation that screening of CRP be a routine part of a patient's global cardiovascular risk assessment and in primary prevention, CRP adds prognostic value to all levels of Framingham risk [90]. In addition to this, CRP was found to be a stronger predictor of CVD incidences that low density lipid levels [91]. CRP will be determined before and after the intervention at weeks 0 and 12. Participants will be sent to have blood samples taken and pathology testing conducted by a reputable pathology collection centre.

\section{Participant diary}

Participants will also be asked to complete a weekly diary documenting drastic changes in diet, commencement or 
cessation of negative behaviours such as alcohol consumption and smoking, number of hours spent exercising, changes in medication, significant positive or negative life events, adverse events, and compliance to yoga program. These behaviours will be monitored by open-ended questions to be completed weekly. This data will be presented for a descriptive synthesis only with compliance to yoga sessions and adverse events, coded into a binary yes/no format, to be considered for inclusion in analysis of covariance (ANCOVA) models as covariates.

\section{Safety and adherence}

In addition to data collected from participant diaries, each assessment visit will detail any information pertaining to adverse events and yoga session compliance will be monitored through class attendance. As stated previously, this data will be included for ANCOVA models as covariates.

\section{Statistical analysis}

Analysis is to be performed using the $\mathrm{R}$ statistics package (version 3.1.1). All data will be inspected visually and statistically for normality (skewness and kurtosis between -1 and +1 ). Analysis of variance (ANOVA) and chi-squared tests of independence will be used to check for any differences between groups at study entry, any differences found here will be controlled for in that outcome analysis. Outcome analysis will take the form of ANCOVAs to detect changes between the experimental and control groups at post- treatment while controlling for baseline values and other possible confounders such as age, gender, time since cardiac incident, time since phase-2 CR completion and current exercise regimen or phase-3 CR participation. Multiple imputations will be used to impute missing data for participants with less than $10 \%$ missing data. An intention to treat analysis in which all missing data will be managed with multiple imputations will be conducted along with a separate per protocol analysis in which those with greater than $10 \%$ missing data or less than $60 \%$ yoga session attendance will be excluded. A p-value of less than 0.05 will be considered statistically significant.

\section{Discussion}

Secondary prevention is an integral aspect regarding the comprehensive care of patients with CVD. Although it has been shown that $\mathrm{CR}$ is effective in positively modifying cardiac risk factors and reducing subsequent cardiac mortality, these benefits appear to plateau and gradually decrease upon completion of CR [92]. As noted by Gupta et al. [93] benefits achieved during CR programs are potentially sustainable at a one year follow up, however, minimal improvement across outcome measures was noted and significant regression was seen in important variables such as 6-minute walk distance, body mass index, diet scores, and smoking status. This is corroborated by evidence from Willich et al. [94] and Boesch et al. [95] who also reported worsening of lipid control at longterm follow points. According to adherence reports by Bittner et al. [96] and Ljubic et al. [97], approximately 50\% of $\mathrm{CR}$ graduates do not maintain adherence to regular physical activity 5-6 months post-phase $2 \mathrm{CR}$ and further highlights that this poor adherence may be associated with higher levels of psychosocial distress such as depression, anxiety, and stress. Given that numerous studies emphasis the capacity of yoga in positively modifying cardiovascular risk factors [35,36,38-45] in addition to psychosocial attenuation [28-34,98], its application in post-cardiac rehabilitation may assist in sustaining and further supplementing the beneficial effects of phase $2 \mathrm{CR}$. As such, this study will aim to determine the effect of yoga practice on psychosocial, cardiovascular and cognitive function in postphase 2 cardiac rehabilitation patients and is expected to provide insight into the short term impact of yoga on traditional and relatively novel cardiovascular risk factors and prognostic markers. In addition, these findings may also provide evidence supporting the incorporation of yoga into standardised CR programs as a practical adjunct to improve the management of psychosocial symptoms associated with CV events in addition to improving patients' cognitive and cardiovascular functions.

\section{Competing interests}

BM is the owner of a commercial yoga studio, Yoga Synergy Pty Ltd.

\section{Authors' contributions}

$D C, H K$ and $A Y$ conceived the study. AY drafted the manuscript. BM and BC designed the yoga intervention. All authors contributed to the study design and protocol preparation. All authors have read and approved the final manuscript.

\section{Author details}

${ }^{1}$ National Institute of Complementary Medicine, School of Science and Health, University of Western Sydney, Locked Bag 1797, Penrith, NSW 2751 Australia. ${ }^{2}$ Cardiac Health Institute, Eastwood, Australia. ${ }^{3}$ Departments of Cardiology, Westmead and Blacktown Hospitals, Sydney, Australia. ${ }^{4}$ Yoga Synergy, Sydney, Australia. ${ }^{5}$ School of Psychology, University of Sydney, Sydney, Australia.

Received: 28 May 2014 Accepted: 15 October 2014

Published: 24 October 2014

\section{References}

1. Cardiovascular diseases (CVDs): Fact sheet No 317. 2011. In http://www who.int/mediacentre/factsheets/fs317/en/index.html.

2. Kessler RC, Angermeyer M, Anthony JC, DE GRAAF R, Demyttenaere $K$ Gasquet I, DE GIROLAMO G, Gluzman S, Gureje O, Haro JM: Lifetime prevalence and age-of-onset distributions of mental disorders in the World Health Organization's World Mental Health Survey Initiative. World Psychiatry 2007, 6(3):168.

3. Vogelzangs $N$, Seldenrijk A, Beekman ATF, van Hout HPJ, de Jonge $P$, Penninx BWJH: Cardiovascular disease in persons with depressive and anxiety disorders. J Affect Disord 2010, 125(1-3):241-248.

4. Fan AZ, Strine TW, Jiles R, Mokdad AH: Depression and anxiety associated with cardiovascular disease among persons aged 45 years and older in 38 states of the United States, 2006. Prev Med 2008, 46(5):445-450. 
5. Kolman L, Shin NM, Krishnan SM, Schwartz S, Gracik T, Jackson EA, Rubenfire M: Psychological distress in cardiac rehabilitation participants. J Cardiopulm Rehabil Prev 2011, 31(2):81

6. Milani RV, Lavie CJ: Impact of cardiac rehabilitation on depression and its associated mortality. Am J Med 2007, 120(9):799-806.

7. Bonnet F, Irving K, Terra JL, Nony P, Berthez ne F, Moulin P: Anxiety and depression are associated with unhealthy lifestyle in patients at risk of cardiovascular disease. Atherosclerosis 2005, 178(2):339-344.

8. Roest AM, Martens EJ, de Jonge P, Denollet J: Anxiety and risk of incident coronary heart disease: a meta-analysis. J Am Coll Cardiol 2010, 56(1):38-46.

9. Dickens C, McGowan L, Percival C, Tomenson B, Cotter L, Heagerty A, Creed $\mathrm{F}$ : Contribution of depression and anxiety to impaired health-related quality of life following first myocardial infarction. Br J Psychiatry 2006, 189(4):367-372.

10. Clark LA, Watson D: Theoretical and empirical issues in differentiating depression from anxiety. New Haven: Lawrence Erlbaum Associates Inc; 1991.

11. Lovibond PF, Lovibond SH: The structure of negative emotional states: Comparison of the Depression Anxiety Stress Scales (DASS) with the Beck Depression and Anxiety Inventories. Behav Res Ther 1995, 33(3):335-343.

12. Schwartz AR, Gerin W, Davidson KW, Pickering TG, Brosschot JF, Thayer JF, Christenfeld N, Linden W: Toward a causal model of cardiovascular responses to stress and the development of cardiovascular disease. Psychosom Med 2003, 65(1):22.

13. Lavie CJ, Milani RV: Prevalence of anxiety in coronary patients with improvement following cardiac rehabilitation and exercise training. Am J Cardiol 2004, 93(3):336-339.

14. Rozanski A, Blumenthal JA, Kaplan J: Impact of psychological factors on the pathogenesis of cardiovascular disease and implications for therapy. Circulation 1999, 99(16):2192-2217.

15. Martens EJ, de Jonge P, Na B, Cohen BE, Lett H, Whooley MA: Scared to death? Generalized anxiety disorder and cardiovascular events in patients with stable coronary heart disease: the heart and soul study. Arch Gen Psychiatry 2010, 67(7):750.

16. Grippo AJ, Johnson AK: Stress, depression and cardiovascular dysregulation: a review of neurobiological mechanisms and the integration of research from preclinical disease models. Stress 2009, 12(1):1-21.

17. Chrousos GP: Stress and disorders of the stress system. Nat Rev Endocrinol 2009, 5(7):374-381.

18. Brotman DJ, Golden SH, Wittstein IS: The cardiovascular toll of stress. Lancet 2007, 370(9592):1089-1100.

19. Benninghoven D, Kaduk A, Wiegand U, Specht T, Kunzendorf S, Jantschek G: Influence of anxiety on the course of heart disease after acute myocardial infarction-risk factor or protective function? Psychother Psychosom 2006, 75(1):56-61

20. Shen BJ, Myers HF, McCreary CP: Psychosocial predictors of cardiac rehabilitation quality-of-life outcomes. J Psychosom Res 2006, 60(1):3-11.

21. Balady GJ, Williams MA, Ades PA, Bittner V, Comoss P, Foody JAM, Franklin B, Sanderson B, Southard D: Core components of cardiac rehabilitation/ secondary prevention programs: 2007 update. A scientific statement from the American Heart Association Exercise, Cardiac Rehabilitation, and Prevention Committee, the Council on Clinical Cardiology; the Councils on Cardiovascular Nursing, Epidemiology and Prevention, and Nutrition, Physical Activity, and Metabolism; and the American Association of Cardiovascular and Pulmonary Rehabilitation. Circulation 2007, 115(20):2675-2682

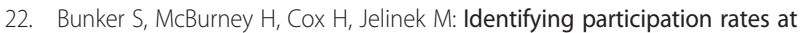
outpatient cardiac rehabilitation programs in Victoria, Australia J Cardiopulm Rehabil Prev 1999, 19(6):334.

23. Scott IA, Lindsay KA, Harden HE: Utilisation of outpatient cardiac rehabilitation in Queensland. Med J Aust 2003, 179(7):341-345.

24. Pinto BM, Goldstein MG, Papandonatos GD, Farrell N, Tilkemeier P, Marcus $\mathrm{BH}$, Todaro JF: Maintenance of exercise after phase II cardiac rehabilitation: a randomized controlled trial. Am J Prev Med 2011, 41(3):274-283

25. Bock BC, Carmona-Barros RE, Esler JL, Tilkemeier PL: Program participation and physical activity maintenance after cardiac rehabilitation. Behav Modif 2003, 27(1):37-53.

26. Kovoor P, Lee AKY, Carrozzi F, Wiseman V, Byth K, Zecchin R, Dickson C, King $M$, Hall J, Ross DL: Return to full normal activities including work at two weeks after acute myocardial infarction. Am J Cardiol 2006, 97(7):952-958.

27. La Forge R: Mind-body fitness: encouraging prospects for primary and secondary prevention. J Cardiovasc Nurs 1997, 11(3):53.

28. Blumenthal JA, Emery CF, Madden DJ, George LK, Coleman RE, Riddle MW, McKee DC, Reasoner J, Williams RS: Cardiovascular and behavioral effects of aerobic exercise training in healthy older men and women. $J$ Gerontol 1989, 44(5):M147.

29. Smith C, Hancock H, Blake-Mortimer J, Eckert K: A randomised comparative trial of yoga and relaxation to reduce stress and anxiety. Complement Ther Med 2007, 15(2):77-83.

30. Michalsen A, Grossman P, Acil A, Langhorst J, Lüdtke R, Esch T, Stefano GB, Dobos GJ: Rapid stress reduction and anxiolysis among distressed women as a consequence of a three-month intensive yoga program. Med Sci Monit 2005, 11(12):561.

31. Uebelacker LA, Epstein-Lubow G, Gaudiano BA, Tremont G, Battle CL, Miller IW: Hatha yoga for depression: critical review of the evidence for efficacy, plausible mechanisms of action, and directions for future research. J Psychiatr Pract 2010, 16(1):22.

32. Da Silva $T L$, Ravindran $L N$, Ravindran AV: Yoga in the treatment of mood and anxiety disorders: a review. Asian J Psychiatr 2009, 2(1):6-16.

33. Chong C, Tsunaka M, Tsang H, Chan EP, Cheung WM: Effects of yoga on stress management in healthy adults: a systematic review. Altern Ther Health Med 2011, 17(1):32-38.

34. Cramer H, Lauche R, Langhorst J, Dobos G: Yoga for depression: a systematic review and meta analysis. Depress Anxiety 2013, 30(11):1068-1083.

35. Hartley L, Dyakova M, Holmes J, Clarke A, Lee MS, Ernst E, Rees K: Yoga for the primary prevention of cardiovascular disease. Cochrane Systematic Review 2014, 5:1-37.

36. Cramer H, Lauche R, Haller H, Dobos G, Michalsen A: A systematic review of yoga for heart disease. Eur J Prev Cardio 2014, 0(00):1-12.

37. Cramer H, Lauche R, Haller H, Steckhan N, Michalsen A, Dobos G: Effects of yoga on cardiovascular disease risk factors: a systematic review and meta-analysis. Int J Cardio/ 2014, 173(2):170-183.

38. Mahajan A, Reddy K, Sachdeva U: Lipid profile of coronary risk subjects following yogic lifestyle intervention. Indian Heart J 1999, 51(1):37.

39. Michalsen A, Dob G: Beneficial effects of lyengar yoga in patients with stress, stress-related disorders and cardiovascular risk-implications of recent research. Scientific Evidence on the Therapeutic Efficacy of lyengar Yoga 2007, 14

40. Pullen PR, Nagamia SH, Mehta PK, Thompson WR, Benardot D, Hammoud R, Parrott JM, Sola S, Khan BV: Effects of yoga on inflammation and exercise capacity in patients with chronic heart failure. J Card Fail 2008, 14(5):407-413.

41. Schmidt T, Wijga A, Von Zur MA, Brabant G, Wagner T: Changes in cardiovascular risk factors and hormones during a comprehensive residential three month kriya yoga training and vegetarian nutrition. Acta Physiol Scand Suppl 1997, 640:158.

42. Vijayalakshmi P, Madanmohan BAB, Patil A, Babu K: Modulation of stress induced by isometric handgrip test in hypertensive patients following yogic relaxation training. Indian J Physiol Pharmacol 2004, 48(1):59-64.

43. Manchanda S, Narang R, Reddy K, Sachdeva U, Prabhakaran D, Dharmanand S, Rajani M, Bijlani R: Retardation of coronary atherosclerosis with yoga lifestyle intervention. J Assoc Physicians India 2000, 48(7):687.

44. Khattab K, Khattab AA, Ortak J, Richardt G, Bonnemeier H: lyengar yoga increases cardiac parasympathetic nervous modulation among healthy yoga practitioners. Evid Based Complement Altern Med 2007, 4(4):511-518.

45. Cheema BS, Houridis A, Busch L, Raschke-Cheema V, Melville GW, Marshall PW, Chang D, Machliss B, Lonsdale C, Bowman J: Effect of an office worksite-based yoga program on heart rate variability: outcomes of a randomized controlled trial. BMC Complement Altern Med 2013, 13(1):82

46. Borg-Olivier S, Machliss B: Applied Anatomy \& Physiology of Yoga. Sydney: Yoga Synergy Pty Limited; 2007.

47. Dahle $\mathrm{CL}$, Jacobs BS, Raz N: Aging, vascular risk, and cognition: blood glucose, pulse pressure, and cognitive performance in healthy adults. Psychol Aging 2009, 24(1):154.

48. Pase MP, Pipingas A, Kras M, Nolidin K, Gibbs AL, Wesnes KA, Scholey AB, Stough $C$ : Healthy middle-aged individuals are vulnerable to cognitive deficits as a result of increased arterial stiffness. J Hypertens 2010, 28(8):1724. 
49. Grodstein F: Cardiovascular risk factors and cognitive function. Alzheimers Dement 2007, 3(2):S16-S22.

50. Cohen RA, Moser DJ, Clark MM, Aloia MS, Cargill BR, Stefanik S, Albrecht A, Tilkemeier P, Forman DE: Neurocognitive functioning and improvement in quality of life following participation in cardiac rehabilitation. Am J Cardiol 1999, 83(9):1374-1378.

51. Lovibond SH, Lovibond PF: Manual for the Depression Anxiety Stress Scales. In Sydney: Psychology Foundation; 1995 [www.psy.unsw.edu.au/dass/]. ISBN 7334-1423-0.

52. Sivasankaran S, Pollard-Quintner S, Sachdeva R, Pugeda J, Hoq SM, Zarich SW: The effect of a six-week program of yoga and meditation on brachial artery reactivity: Do psychosocial interventions affect vascular tone? Clin Cardiol 2006, 29(9):393-398.

53. Andrew MJ, Baker RA, Kneebone AC, Knight JL: Mood state as a predictor of neuropsychological deficits following cardiac surgery. J Psychosom Res 2000, 48(6):537-546.

54. Lovibond S, Lovibond PF: Manual for the depression anxiety stress scales. Sydney: Psychology Foundation of Australia; 1996.

55. Ware JE, Gandek B: Overview of the SF-36 health survey and the international quality of life assessment (IQOLA) project. J Clin Epidemiol 1998, 51(11):903-912.

56. McHorney CA, War JE Jr, Lu JFR, Sherbourne CD: The MOS 36-item ShortForm Health Survey (SF-36): III. Tests of data quality, scaling assumptions, and reliability across diverse patient groups. Med Care 1994, 32(1):40-66.

57. Jette DU, Downing J: Health status of individuals entering a cardiac rehabilitation program as measured by the medical outcomes study 36-item short-form survey (SF-36). Phys Ther 1994, 74(6):521-527.

58. Thayer JF, Yamamoto SS, Brosschot JF: The relationship of autonomic imbalance, heart rate variability and cardiovascular disease risk factors. Int J Cardiol 2010, 141(2):122-131.

59. Kleiger RE, Miller JP, Bigger JT Jr, Moss AJ: Decreased heart rate variability and its association with increased mortality after acute myocardial infarction. Am J Cardiol 1987, 59(4):256-262.

60. Tsuji H, Venditti FJ Jr, Manders ES, Evans JC, Larson MG, Feldman CL, Levy D: Reduced heart rate variability and mortality risk in an elderly cohort. The Framingham Heart Study. Circulation 1994, 90(2):878-883.

61. Liao D, Carnethon M, Evans GW, Cascio WE, Heiss G: Lower heart rate variability is associated with the development of coronary heart disease in individuals with diabetes. Diabetes 2002, 51(12):3524-3531.

62. Camm AJ, Pratt CM, Schwartz PJ, Al-Khalidi HR, Spyt MJ, Holroyde MJ, Karam R, Sonnenblick EH, Brum JMG: Mortality in patients after a recent myocardial infarction. Circulation 2004, 109(8):990-996.

63. Carney RM, Freedland KE: Depression and heart rate variability in patients with coronary heart disease. Cleve Clin J Med 2009, 76(Suppl 2):S13-S17.

64. Miu AC, Heilman RM, Miclea M: Reduced heart rate variability and vagal tone in anxiety: trait versus state, and the effects of autogenic training. Auton Neurosci 2009, 145(1):99-103.

65. Camm AJ, Malik M, Bigger J, Breithardt G, Cerutti S, Cohen R, Coumel P, Fallen E, Kennedy H, Kleiger R: Heart rate variability: standards of measurement, physiological interpretation, and clinical use. Circulation 1996, 93(5):1043-1065.

66. Laurent S, Cockcroft J, Van Bortel L, Boutouyrie P, Giannattasio C, Hayoz D, Pannier B, Vlachopoulos C, Wilkinson I, Struijker-Boudier H: Expert consensus document on arterial stiffness: methodological issues and clinical applications. Eur Heart J 2006, 27(21):2588-2605.

67. Boutouyrie P, Tropeano Al, Asmar R, Gautier I, Benetos A, Lacolley P, Laurent $S$ : Aortic stiffness is an independent predictor of primary coronary events in hypertensive patients. Hypertension 2002, 39(1):10-15.

68. Cruickshank K, Riste L, Anderson SG, Wright JS, Dunn G, Gosling RG: Aortic pulse-wave velocity and its relationship to mortality in diabetes and glucose intolerance. Circulation 2002, 106(16):2085-2090.

69. Mattace-Raso FUS, van der Cammen TJM, Hofman A, van Popele NM, Bos ML, Schalekamp MADH, Asmar R, Reneman RS, Hoeks APG, Breteler M: Arterial stiffness and risk of coronary heart disease and stroke. Circulation 2006, 113(5):657-663.

70. Hansen TW, Staessen JA, Torp-Pedersen C, Rasmussen S, Thijs L, Ibsen H, Jeppesen J: Prognostic value of aortic pulse wave velocity as index of arterial stiffness in the general population. Circulation 2006, 113(5):664-670.

71. Weber T, Ammer M, Rammer M, Adji A, O'Rourke MF, Wassertheurer S, Rosenkranz S, Eber B: Noninvasive determination of carotid-femoral pulse wave velocity depends critically on assessment of travel distance: a comparison with invasive measurement. J Hypertens 2009, 27(8):1624.
72. Stein JH, Korcarz CE, Hurst RT, Lonn E, Kendall CB, Mohler ER, Najjar SS, Rembold CM, Post WS: Use of carotid ultrasound to identify subclinical vascular disease and evaluate cardiovascular disease risk: a consensus statement from the American Society of Echocardiography Carotid Intima-Media Thickness Task Force endorsed by the Society for Vascular Medicine. J Am Soc Echocardiogr 2008, 21(2):93-111.

73. Touboul PJ, Hennerici M, Meairs S, Adams H, Amarenco P, Bornstein N, Csiba L, Desvarieux M, Ebrahim S, Fatar M: Mannheim carotid intima-media thickness consensus (2004-2006). Cerebrovasc Dis 2007, 23(1):75-80.

74. Robertson CM, Fowkes FGR, Price JF: Carotid intima-media thickness and the prediction of vascular events. Vasc Med 2012, 17(4):239-248.

75. Wesnes K, Ward T, McGinty A, Petrini O: The memory enhancing effects of a ginkgo biloba/panax ginseng combination in healthy middle-aged volunteers, Psychopharmacol.(Berl) 152 (2000). Full Text via CrossRef View Record in Scopus| Cited By in Scopus 2000, 143:353-361.

76. Sahakian B, Owen $A$ : Computerized assessment in neuropsychiatry using CANTAB: discussion paper. J R Soc Med 1992, 85(7):399.

77. Robbins T, James M, Owen A, Sahakian B, Mclnnes L, Rabbitt P: Cambridge Neuropsychological Test Automated Battery (CANTAB): a factor analytic study of a large sample of normal elderly volunteers. Dement Geriatr Cogn Disord 1994, 5(5):266-281

78. Simpson PM, Surmon D, Wesnes KA, Wilcock G: The cognitive drug research computerized assessment system for demented patients: a validation study. Int J Geriatr Psychiatry 1991, 6(2):95-102.

79. Castelli WP, Garrison RJ, Wilson PWF, Abbott RD, Kalousdian S, Kannel WB: Incidence of coronary heart disease and lipoprotein cholesterol levels. JAMA 1986, 256(20):2835-2838.

80. Williams KJ, Tabas I: The response-to-retention hypothesis of early atherogenesis. Arterioscler Thromb Vasc Biol 1995, 15(5):551-561.

81. Glass CK, Witztum JL: Atherosclerosis: the road ahead review. Cell 2001 104(4):503-516.

82. Chapman MJ, Ginsberg HN, Amarenco P, Andreotti F, Borén J, Catapano AL, Descamps OS, Fisher E, Kovanen PT, Kuivenhoven JA: Triglyceride-rich lipoproteins and high-density lipoprotein cholesterol in patients at high risk of cardiovascular disease: evidence and guidance for management. Eur Heart J 2011, 32(11):1345

83. Psaty BM, Anderson M, Kronmal RA, Tracy RP, Orchard T, Fried LP, Lumley T, Robbins J, Burke G, Newman AB: The association between lipid levels and the risks of incident myocardial infarction, stroke, and total mortality: The Cardiovascular Health Study. J Am Geriatr Soc 2004, 52(10):1639-1647.

84. Laakso M: Cardiovascular disease in type 2 diabetes from population to man to mechanisms. Diabetes Care 2010, 33(2):442-449.

85. Fuller JH, Shipley MJ, Rose G, Jarrett RJ, Keen H: Coronary-heart-disease risk and impaired glucose tolerance The Whitehall Study. Lancet 1980, 315(8183):1373-1376.

86. Donahue R, Abbott R, Reed D, Yano K: Postchallenge glucose concentration and coronary heart disease in men of Japanese ancestry. Honolulu Heart Program. Diabetes 1987, 36(6):689-692.

87. Singer D, Nathan D, Anderson K, Wilson P, Evans J: Association of HbA1c with prevalent cardiovascular disease in the original cohort of the Framingham Heart Study. Diabetes 1992, 41(2):202-208.

88. Ridker PM, Hennekens CH, Buring JE, Rifai N: C-reactive protein and other markers of inflammation in the prediction of cardiovascular disease in women. N Engl J Med 2000, 342(12):836-843.

89. Ridker PM, Rifai N, Stampfer MJ, Hennekens CH: Plasma concentration of interleukin- 6 and the risk of future myocardial infarction among apparently healthy men. Circulation 2000, 101(15):1767-1772.

90. Blake GJ, Rifai N, Buring JE, Ridker PM: Blood pressure, C-reactive protein, and risk of future cardiovascular events. Circulation 2003, 108(24):2993-2999.

91. Ridker PM, Rifai N, Rose L, Buring JE, Cook NR: Comparison of C-reactive protein and low-density lipoprotein cholesterol levels in the prediction of first cardiovascular events. N Engl J Med 2002, 347(20):1557-1565.

92. Chase J-AD: Systematic review of physical activity intervention studies after cardiac rehabilitation. J Cardiovasc Nurs 2011, 26(5):351-358.

93. Gupta R, Sanderson BK, Bittner V: Outcomes at one-year follow-up of women and men with coronary artery disease discharged from cardiac rehabilitation: what benefits are maintained? J Cardiopulm Rehabil Prev 2007, 27(1):11-18

94. Willich S, Müller-Nordhorn J, Kulig M, Binting S, Gohlke H, Hahmann H, Bestehorn K, Krobot K, Völler H: Cardiac risk factors, medication, and 
recurrent clinical events after acute coronary disease. A prospective cohort study. Eur Heart J 2001, 22(4):307-313.

95. Boesch C, Myers J, Habersaat A, llarraza H, Kottman W, Dubach P:

Maintenance of exercise capacity and physical activity patterns 2 years after cardiac rehabilitation. J Cardiopulm Rehabil Prev 2005, 25(1):14-21.

96. Bittner V, Oberman A: Efficacy studies in coronary rehabilitation. Cardiol Clin 1993, 11(2):333-347.

97. Ljubic MA, Deane FP, Zecchin RP, Denniss R: Motivation, psychological distress and exercise adherence following myocardial infarction. Aust J Rehabil Counsell 2006, 12(1):21.

98. Kirkwood G, Rampes H, Tuffrey V, Richardson J, Pilkington K: Yoga for anxiety: a systematic review of the research evidence. Br J Sports Med 2005, 39(12):884-891.

doi:10.1186/1472-6882-14-411

Cite this article as: Yeung et al: Randomised controlled trial of a

12 week yoga intervention on negative affective states, cardiovascular and cognitive function in post-cardiac rehabilitation patients. BMC

Complementary and Alternative Medicine 2014 14:411.

\section{Submit your next manuscript to BioMed Central and take full advantage of:}

- Convenient online submission

- Thorough peer review

- No space constraints or color figure charges

- Immediate publication on acceptance

- Inclusion in PubMed, CAS, Scopus and Google Scholar

- Research which is freely available for redistribution 